\title{
GINÁSTICA LABORAL COMO PROMOTORA DE QUALIDADE DE VIDA: AVALIAÇÃO DE PROJETOS E FATORES CRÍTICOS DE SUCESSO
}

Ricardo Lima Bastos, Universidade Estadual de Campinas - UNICAMP, Campinas, São Paulo, Brasil

Gustavo Luis Gutierrez, Universidade Estadual de Campinas - UNICAMP, Campinas, São Paulo, Brasil

\section{RESUMO}

É crescente entre as empresas a preocupação com sua imagem social e qualidade de vida do trabalhador. Da mesma forma é significante o crescimento dos programas de ginástica laboral nas empresas visando à melhora da saúde e da qualidade de vida do trabalhador, além do aumento da produtividade e redução de lesões e consequentemente o absenteísmo. Não são muitos os artigos sobre ginástica laboral e nestes poucos tem como tema principal os benefícios da ginástica laboral em diferentes facetas. Os profissionais de educação física, em grande parte, possuem um perfil diferenciado do ambiente corporativo fato que pode levá-lo a cometer equívocos na implantação e gerenciamento dos programas. Sendo assim, se torna importante e reflexão sobre o programa em conjunto com a empresa. Neste trabalho pretendemos conceituar os Fatores Críticos de Sucesso e refletir acerca da avaliação dos projetos de ginástica laboral em sua implantação e desenvolvimento, pois estas avaliações processuais são cada vez mais frequentes no âmbito empresarial com o objetivo de economizar tempo, dinheiro e atingir os objetivos em prazos cada vez mais curtos.

Palavras-Chave: Ginástica laboral; Qualidade de vida na empresa; Fatores críticos de sucesso.

\section{GYM WORK AS A PROMOTER OF QUALITY OF LIFE: ASSESSMENT OF PROJECTS AND CRITICAL SUCCESS FACTORS}

\begin{abstract}
ABSTRAT
A growing concern among companies with their social image and quality of life employes. Equally significant is the growth of labor gymnastics programs in companies aiming at improving health and quality of lives of workers, in addition to increased productivity and reduced absenteeism and consequently the injury. There are quite few articles on labor gymnastics and majority has as its main theme the benefits of labor gymnastics in different facets. The physical education teachers, in large part, have a distinctive profile of the corporate environment because it can lead you to commit mistakes in the implementation and management of programs. Thus, it becomes important reflection on the program in conjunction with the company. In this paper I intend to conceptualize the Critical Success Factors and reflect on the projects labor gymnastics in its implementation and development, as these assessments are increasingly frequent business in order to save time, money and achieve goals in increasingly shorter time limits.
\end{abstract}


Key-Words: Labor Gymnastics; Quality of life in the company; Critical success factors.

\section{TRABAJO GYM COMO PROMOTOR DE LA CALIDAD DE VIDA: LA EVALUACIÓN DE PROYECTOS Y FACTORES CRÍTICOS DE ÉXITO}

\section{RESUMEN}

Una preocupación creciente entre las empresas con su imagen social y la calidad de vida del trabajador. Igualmente significativo es el crecimiento de los programas de gimnasia en las empresas destinadas a mejorar la salud y la calidad de vida de los trabajadores, además de una mayor productividad y reducción del absentismo y, en consecuencia el daño. Hay muchos artículos en la gimnasia la mayoría tiene como tema principal los beneficios de la gimnasia en diferentes facetas. Los profesores de educación física, en gran parte, tienen un perfil propio de los entornos corporativos, ya que te puede llevar a cometer errores en la ejecución y gestión de programas. Por lo tanto, es importante y la reflexión sobre el programa en conjunto con la empresa. En este artículo me propongo conceptualizar los factores críticos de éxito y reflexionar sobre los proyectos de la gimnasia en su aplicación y desarrollo, ya que estas evaluaciones son un negocio cada vez más frecuentes con el fin de ahorrar tiempo, dinero y alcanzar las metas en plazos cada vez más cortos.

Palabras-Clave: Gimnasia; Calidad de vida en los negocios; Factores críticos de éxito. 


\section{INTRODUÇÃO}

É crescente no meio empresarial a preocupação com sua imagem social e a saúde do trabalhador. $\mathrm{O}$ crescimento dos programas de ginástica laboral nas empresas visando à melhora da saúde e da qualidade de vida dos funcionários representa o avanço destas áreas no meio corporativo. A empresa que contrata um programa de ginástica laboral acredita que, para além dos benefícios do trabalhador, ela também obterá aumento da produtividade e redução do quadro de lesões entre os funcionários, seguindo a lógica da busca de eficiência. Para justificar esta demanda artigos comprovam os benefícios da ginástica laboral em diferentes âmbitos tais como trabalho noturno, administrativos, esforços repetitivos, indústrias e na prevenção de lesões. ${ }^{1-3}$

Ainda nesta lógica é cada vez maior o número de empresas que procuram avaliar a implantação e gerenciamento de seus projetos e programas, a fim de garantir o investimento além de economizar tempo, dinheiro e obter qualidade. ${ }^{4}$ Nos estudos referentes a estes trabalhos é aplicado o conceito Fatores Críticos de Sucesso. O entendimento do conceito de fator crítico, largamente utilizado na administração, permite ao educador físico uma melhor compreensão de sua atuação na empresa, além de uma aproximação com o meio devido à possibilidade de compreender seu funcionamento de maneira lógica e estruturada.

Um ponto importante é que os profissionais de educação física, em sua maioria, possuem um perfil diferenciado em relação ao ambiente corporativo, o que em alguns casos, ocasiona "choques" de idéias, conduta e plano de ação de um programa de qualidade de vida. O profissional de educação física deve compreender estas nuances afim poder dialogar, além de detectar os fatores indispensáveis na implantação dos programas para um bom gerenciamento. Assim este texto objetiva auxiliar o profissional de educação física no diagnóstico, implantação e desenvolvimento dos programas de ginástica laboral identificando e compreendendo os fatores críticos de sucesso a partir da lógica corporativa, bem como passar um pouco de conhecimento acerca de um ambiente cujas características fundamentais podem parecer estranhas para profissionais com vivências marcadas, basicamente, pelos ambientes acadêmico e esportivo. 


\section{QUALIDADE DE VIDA}

Qualidade de vida é um termo recente que tem sido muito em empregado tanto no meio acadêmico quanto pelo público em geral. É um conceito que tenta definir uma área que está em formação e é relativamente grande, pois parte da interface entre áreas distintas, incorporando estudos profissionais variados, e de natureza polissêmica. ${ }^{5}$

É crescente o número de estudos sendo realizados sobre qualidade de vida e a área ganha um corpo teórico cada vez mais denso e definido. Dentro do conceito mais amplo de Qualidade de Vida, é percebida em pesquisa bibliográfica uma dimensão importante, definida como o "modo de vida" que consiste nas necessidades básicas para a subsistência de uma população, como saneamento, renda e serviços. ${ }^{6}$

A partir desta, outras duas expressões se articulam referenciando a dinâmica sócioeconômica de produção, circulação e consumo de bens. Assim temos que Condições de Vida como fatores mais gerais na sociedade que influem na vida da população como acesso aos serviços básicos, educação, saúde, empregabilidade. Estilo de vida corresponde às particularidades dos indivíduos como tomada decisões pessoais, ou também a um grupo amigos e famílias que possuem normas próprias, hábitos e valores diferentes. ${ }^{7} \mathrm{O}$ estilo de vida é composto por diversos fatores. As adaptações biológicas e culturais que os indivíduos experimentam durante toda a vida resultam em mudanças comportamentais, que por sua vez, podem influir na saúde e bem estar geral. ${ }^{5}$

Há vários instrumentos e indicadores para mensurar qualidade de vida de um grupo específico ou de uma cidade ou país. Como exemplo temos o Índice de desenvolvimento Humano (IDH), o IDHC - ou IDH corrigido que teoricamente ajusta o IDH depurando-o da inclusão do PIB em seu cálculo. ${ }^{5}$ O IDH abarca três aspectos de uma nação ou cidade e compara seus dados de riqueza, educação e expectativa de vida. Este índice vem sendo usado pela ONU - Organização das Nações Unidas - que classifica os países membros. Em termos de avaliação subjetiva da qualidade de vida individualizada, na atualidade, o instrumento mais aceito é o World Health Organization Quality of Life (WHO; QOL 100), criado em 1995 pela Divisão da Saúde Mental da OMS na tentativa de otimizar os resultados das avaliações. O instrumento foi desenvolvido para responder às percepções das pessoas, posição na vida em seu 
contexto cultural, seus valores e suas expectativas. Ele possui seis domínios ou facetas: Domínio Físico, Domínio Psicológico, Nível de Independência, Relações Sociais, Ambiente e Aspectos Espirituais. ${ }^{8}$

Os estudos demonstram certa relativização histórica e sociocultural da Qualidade de Vida. Historicamente, uma determinada sociedade pode apresentar parâmetros diferentes conforme sua evolução econômica ou tecnológica. O aspecto social influencia na medida em que ele delimita a construção, a hierarquia e manutenção das classes sociais ou não, influenciando, assim, a qualidade de vida de seus indivíduos. Do ponto de vista cultural a percepção de qualidade de vida é modificada, pois está diretamente relacionada com as necessidades destes indivíduos. ${ }^{5}$ Logo, uma complexidade de fatores tem de ser levada em conta ao se tentar mensurar Qualidade de Vida. Entendemos também que muitos deles não são fáceis de serem contabilizados. Outro ponto importante é que muitos destes fatores não são estáticos e mudam conforme a sociedade e os indivíduos que a compõem.

\subsection{Qualidade de vida, trabalho e ambiente corporativo}

O trabalho com suas e regras em formato próximo ao que conhecemos teve as raízes de sua teoria moldadas a partir das idéias dos economistas clássicos tendo em vista os problemas da época. ${ }^{9}$ Com sua evolução a qualidade de vida no trabalho sofre alterações, pois ela está diretamente relacionada como posicionamento do administrador e consciência de saúde do trabalhador e as preocupações sociais como um todo. Uma importante figura foi o engenheiro francês Henry Fayol que no início do século XX foi o primeiro a definir administração como sendo um processo similar ao que conhecemos atualmente, ou seja, com suas ações de organizar, planejar e dirigir. O mesmo formulou 14 princípios que regiam sua forma de administrar. ${ }^{10}$ Com isso o funcionamento administrativo ganhou eficiência devido a sua estruturação lógica.

O Taylorismo, corrente do século XX, vem de um engenheiro americano chamado Frederick Winslow Taylor. Sua característica fundamental foi a fragmentação do trabalho onde o funcionário passava a conhecer apenas uma pequena parte do processo o que na época trouxe grandes avanços para os empresários, com fatores como o ganho de tempo e pela redução dos salários Heloani. ${ }^{11}$ Outra importante corrente foi o Fordismo, desenvolvido por Henry Ford. Sua principal característica foi a introdução da Conexões: revista da Faculdade de Educação Física da UNICAMP, Campinas, v. 11, n. 2, p. 208-222, abr./jun. 212 2013. ISSN: 1983-9030 
linha de montagem. Esta reformulação limita o deslocamento do funcionário além de impor o ritmo sobre ele através da esteira, gerando assim maior controle. ${ }^{11}$ A imposição do ritmo para a realização de movimentos repetitivos, monótonos e com velocidade ditada conforme a demanda da empresa, causou um aumento nos números de doenças ocupacionais o seja, aquelas relacionadas ao trabalho. ${ }^{12}$ Aqui houve novamente um grande avanço na produção, porém, com o trabalhador mais preso a máquina e imposto a rotinas mais rígidas. Estas decisões nos mostram que havia pouca preocupação na época com a qualidade de vida do trabalhador.

O processo levou a uma crescente insatisfação do trabalhador devido a estas formas de organização do trabalho, e com isso idéias contrárias começaram a surgir. A Escola de Relações Humanas no Trabalho que possui pesquisas elaboradas por Mayo, pautou-se em uma visão progressista do ser humano, onde ele deveria trabalhar em grupos por ter necessidades sociais a serem satisfeitas. ${ }^{10}$ Outra forma interessante de se pensar o trabalho consiste na Administração da Qualidade Total, elaborada pelo Dr. Armand V. Feingenbaum, e otimizada no Japão após a segunda guerra mundial. Nela todos estão incluídos nos problemas acerca dos padrões de qualidade. É pautada no respeito à capacidade dos trabalhadores, permitindo que seja desenvolvido o potencial dos seres humanos. O modelo pressupõe que funcionários e empresa estão interligados e que todos precisam sentir-se bem trabalhando nela, pois somente assim, poderão utilizar todas as suas capacidades. ${ }^{10}$

Enquanto o Japão buscava relações mais criativas no trabalho, nos Estados Unidos e Europa o fordismo começava a declinar dando lugar ao pós-fordismo. Com as novas exigências do mercado, como a internacionalização da economia e o advento da tecnologia microeletrônica, houve uma cobrança aos trabalhadores para atuar não apenas na manutenção dos equipamentos, mas também na sua programação e desenvolvimento. Surgem, assim, outras formas de gestão da produção, como o volvismo, por exemplo, incorporando elementos de gestão participativa. ${ }^{11}$ Segundo Heloani, ${ }^{11}$ o Brasil se inseriu no pós-fordismo, porém de forma politicamente centralizada, o que desqualificou o trabalho e levou a que muitos programas, ditos participativos, apresentassem resultados medíocres. 
Segundo Gonçalves, Gutierrez e Vilarta ${ }^{13}$ é fundamental conhecer as características da cultura organizacional e do funcionamento das empresas, inclusive daquelas que já possuem projetos com qualidade de vida, pois podem existir práticas a partir de setores de RH e medicina do trabalho, entre outras áreas que buscam trabalhar com a gestão da qualidade de vida. Logo, um programa de ginástica laboral deve somar-se aos que já existem na empresa com objetivo comum. É preciso também entender o trabalho em sua totalidade onde a eficiência depende não só do conhecimento técnico, mas do desenvolvimento do espírito de equipe, de recursos e apoios adequados nas esferas física, mental/intelectual e emocional/psicológica. ${ }^{13}$

\section{GINÁSTICA LABORAL}

A ginástica laboral teve início em 1925, na Polônia SESI. ${ }^{14}$ Neste período era conhecida como ginástica de pausa. Lima ${ }^{15}$ corrobora esta assertiva e acrescenta que alguns anos depois surgiu também na Holanda e na Rússia. Alvarez ${ }^{16}$ nos traz que a Ginástica Laboral teve início na Japão em 1928 com funcionários do correio japonês e tinha o objetivo de descontração e cultivo à saúde. O hábito foi difundido e atualmente um terço dos trabalhadores japoneses exercita-se em seus postos de trabalho. ${ }^{17}$ A partir do início dos anos 60 existiram propostas de ginástica laboral em países como Bulgária, Alemanha Oriental, Suécia e Bélgica, porém somente no Japão houve sua consolidação. ${ }^{14}$

No Brasil esta prática teve início em 1969, por iniciativa de empresários japoneses na Ishikawajima do Brasil Estaleiros S.A. no Rio de Janeiro. Era feita ao ar livre, com os funcionários em grupos e ao som de Tchaikovsky (Ministério da Educação, 1990). A partir daí surgiram projetos como o elaborado pela federação de Estabelecimentos de Ensino Superior em Novo Hamburgo - RS (FEEVALE), intitulado Educação Física Compensatória e Recreação era embasado por exercícios biomecanicamente montados e tinham por objetivo o relaxamento da musculatura. ${ }^{17}$ Houve também um projeto em 1978 entre a FEEVALE e o SESI, que foi chamando de Ginástica Laboral Compensatória, implantado em cinco empresas do Vale dos Sinos. Apesar dos resultados positivos obtidos no estudo e do caráter experimental do projeto, com o seu fim, não foi passado nenhum feedback para a empresa o que causou certo desconforto entre as partes. $^{18}$ 
Após esse período a ginástica Laboral caiu no esquecimento, pois os objetivos iniciais eram apenas de estudo e não época na havia mentalidade que possibilitasse o desenvolvimento dos programas. A partir de 1980 a ginástica laboral começou a ser retomada, tendo uma forte ascensão a partir dos anos $90 .{ }^{17}$ São muitos seus benefícios ilustrados na literatura disponível, bem como no caso do incentivo à prática de atividade física, promoção da saúde e melhora do desempenho profissional. Observa-se uma melhora da qualidade de vida geral e consequentemente, benefícios nos níveis fisiológicos, psicológicos e sociais. ${ }^{19}$ Atualmente, a Ginástica Laboral é classificada quanto ao horário em que é executada e quanto ao seu objetivo. Sendo a preparatória antes de iniciar as atividades profissionais, a compensatória durante o expediente e a relaxante ao término do trabalho. ${ }^{20}$ Em relação aos objetivos, a preparatória busca preparar o trabalhador para a atividade, a compensatória minimiza e previne os vícios posturais, a corretiva restabelece o equilíbrio muscular e articular, e a ginástica de manutenção mantém o equilíbrio fisiomorfológico. ${ }^{21}$

Um objetivo inerente aos estudos acerca da ginástica laboral é o aumento da produtividade. Com globalização têm-se dado mais ênfase ao capital humano, por acreditar que este é o fator decisivo nas organizações, recrutando e gerenciando trabalhadores saudáveis em empresas saudáveis. ${ }^{15}$ A importância da ginástica laboral deve vir junto com seus benefícios. O trabalhador usa seu corpo no trabalho e exercícios são práticas de atividades físicas sistematizadas, que objetivam que o funcionário esteja com o corpo mais preparado para o seu trabalho. Afinal um corpo mais saudável e forte lidará com suas atividades da vida diária de maneira mais amena, em função dos processos fisiológicos adaptativos.

Podemos inferir que o programa de ginástica laboral colabora positivamente na qualidade de vida dos sujeitos e pode também ser entendido como um programa de qualidade de vida: "As organizações burocráticas, e empresas em particular, possuem historicidade, lógica de funcionamento e cultura distintos. A implantação de programas de melhoria de vida, nestes casos, parar obter sucesso, deve levar em conta o que é constitutivo da empresa, que a torna diferente dos outros espaços de sociabilidade." ${ }^{22}$ Segundo Vansan ${ }^{23}$ nos últimos 20 anos muitas empresas que aderiram a programas de ginástica laboral observaram aumento na produtividade além da redução nos custos de Conexões: revista da Faculdade de Educação Física da UNICAMP, Campinas, v. 11, n. 2, p. 208-222, abr./jun. 215 2013. ISSN: 1983-9030 
saúde. Mesmo que o objetivo principal do empresário seja aumentar os lucros, têm-se observado também um aumento da qualidade de vida dos trabalhadores.

Um programa de ginástica laboral, por definição, deve objetivar o aumento da produção, redução do absenteísmo, redução das doenças relacionadas ao trabalho diretamente, tendo presente que existem casos que não se relacionam com o trabalho e que, portanto, não podem ser prevenidas com a ginástica laboral. Estes tópicos devem ser somados às preocupações dos profissionais de educação física e os profissionais da saúde, sem nunca negligenciar a importância do trabalhador. Desta forma, o profissional de educação física deve organizar seu programa de ginástica laboral refletindo sobre os pontos relevantes para o trabalhador e para a empresa. Esse balanço pode ser feito adotando os fatores crítico de cada caso.

\section{FATORES CRÍTICOS DE SUCESSO}

A avaliação de programas e projetos é uma preocupação cada vez maior no meio corporativo, a fim de corrigir metas e economizar tempo e dinheiro. ${ }^{4}$ Desta forma, muitos trabalhos que buscam avaliar projetos no meio corporativo trabalham com o conceito Fatores Críticos de Sucesso. O conceito foi desenvolvido por Ronald Daniel da Mckinsey \& Company em (1961), ${ }^{24}$ e refinado por Jack F. Rockart em (1978), ${ }^{25}$ sendo a partir daí introduzido nas ferramentas de gestão. O termo foi inicialmente utilizado nas áreas de análise de dados e análise de negócios.

O método consiste na identificação de áreas, ou fatores, fundamentais para que a empresa conclua sua missão. O método é baseado em entrevistas, onde o entrevistador de posse dos dados pode confrontá-los e identificar os pontos relevantes. Como todo modelo, este também teve evoluções ao longo dos anos, na busca de mais precisão e dinamismo. Os Fatores Críticos de Sucesso (FCS) podem ser entendidos, por exemplo, como indicadores que monitoram as etapas mais importantes para o desempenho de uma intervenção de gestão, destacando os pontos onde uma falha de processo pode ter maior impacto na busca dos objetivos determinados. Limongi-França, ${ }^{26}$ na análise de qualidade de vida no trabalho apresentada em seu livro (2010), utiliza os FCS como elementos importantes na relação com a administração de empresas, sendo utilizados para balizar a pesquisa apresentada. 
A educação física, através ginástica laboral, deve acompanhar o desenvolvimento do segmento de inserção profissional. Neste sentido, é importante a avaliação da implantação dos programas de ginástica laboral por um viés do âmbito empresarial, mesmo levando em conta que se trata de um instrumental de análise com o qual o profissional de educação física não está acostumado a trabalhar. O esforço para dominar metodologias como a dos FCS pode auxiliar os profissionais de educação física em futuros programas, dotando-os de uma visão mais ampla e correta do processo como um todo, da sua eficácia e da inserção articulada com outras iniciativas da administração.

A clara percepção dos fatores críticos, no âmbito da gestão da qualidade de vida no trabalho, é importante também para a incorporação da ginástica laboral, assim como outras iniciativas do campo, nos modelos de gestão empresarial, ou seja, a empresa já possui uma estrutura complexa de funcionamento e estes fatores auxiliam também no alinhamento do programa com esta estrutura empresarial. De fato, os FCS estão situados entre os objetivos e os resultados, fazendo uma interface para que estes objetivos se tornem nos resultados almejados. ${ }^{26}$ Alguns exemplos de fatores de sucesso podem ser: (a) o grau de inovação do produto ou serviço prestado, (b) as características do mercado alvo, (c) as características do produto ou serviço, (d) fontes de tecnologia, (e) habilidades da empresa, (f) habilidades do líder do projeto, (g) integração, (h) organização dos integrantes do projeto, (i) qualidade na execução do projeto, (j) qualidade de execução de outras atividades. ${ }^{27}$ Os FCS estão ligados à estratégia da empresa e dependem da vontade política dos envolvidos, da adequação da estrutura organizacional e do planejamento estratégico, tático e operacional. Ou seja eles dependem, em grande parte, da maturidade organizacional. ${ }^{22}$

\section{OBSERVAÇÕES FINAIS}

A ginástica laboral ainda é um campo relativamente novo, o que leva a que existam empresas no mercado que aplicam aulas desconexas, sem planejamento prévio. Neste sentido, é importante uma sistematização do programa e sua articulação com o projeto mais amplo de gestão corporativa da qualidade de vida. Cabe, portanto, questionar constantemente os programas de ginástica laboral para que esta se consolide no mercado brasileiro. 
O estudo Irja ${ }^{4}$ examinou os fatores críticos de sucesso e falhas em gerenciamento de projetos, e suas relações com as variáveis do contexto organizacional. Nesta pesquisa, os fatores críticos de sucesso e falhas foram e classificados em quatro grupos de fatores: (a) projeto, (b) gerente de projeto, (c) time de projeto e (d) ambiente. A comunicação foi ranqueada em primeiro lugar, na maioria dos fatores, como relevante ao sucesso do projeto, destacando a comunicação entre equipes nas grandes companhias. O estudo defende ainda que para ter o sucesso em um projeto é necessário além do conhecimento técnico, a necessidade de gestão do conhecimento, liderança e habilidade. Outro ponto importante a se destacar nos programas de ginástica laboral é o apoio dos chefes e a sua aderência ao programa. A possibilidade de avanço das práticas ligadas à ginástica laboral depende da capacidade de seus profissionais para interagir, de forma positiva, com estes ambientes, a partir da sua relação mais específica com a gestão da qualidade de vida na empresa, chegando até o diálogo com as dimensões mais amplas que se articulam para a definição de estratégias e diretrizes que regem a política da organização.

Em suma o profissional de ginástica laboral deve ter em mente que se torna necessário, com a implantação do programa, um constante processo de avaliação tanto das variáveis que se deseja atingir quanto do próprio programa em si. O Quadro 1 ilustra algumas das categorias a serem avaliadas, que podem variar conforme a especificidade de cada ambiente organizacional. 
Quadro 1 - Categorias a serem avaliadas

\begin{tabular}{|c|c|}
\hline Categoria & Itens a serem avaliados \\
\hline \multirow[b]{5}{*}{ Objetivos do programa } & Redução do absenteísmo \\
\hline & Redução de dores \\
\hline & Aumento da produtividade \\
\hline & Prevenção de lesões \\
\hline & Melhora da qualidade de vida \\
\hline \multirow{5}{*}{$\begin{array}{l}\text { Fatores Críticos de } \\
\text { Sucesso }\end{array}$} & Gerente do projeto: apoio ao programa \\
\hline & $\begin{array}{l}\text { Projeto - se está adequado às necessidades } \\
\text { do cliente }\end{array}$ \\
\hline & Participação das chefias \\
\hline & Ambiente - da aula \\
\hline & Competência do instrutor \\
\hline
\end{tabular}

Os objetivos do programa, designados aqui como exemplos, podem ser avaliados por questionários específicos, relatórios e a própria avaliação física dos funcionários envolvidos, conforme as necessidades definidas pelo cliente e/ou detectadas pelo profissional responsável pelo programa.

Já os Fatores Críticos de Sucesso fazem parte da avaliação do próprio programa com relação aos seus objetivos. Acrescentamos aqui a competência do instrutor, pois, no próprio estudo é destacada a importância do conhecimento técnico e capacidade de comunicação como elementos fundamentais nas aulas de ginástica laboral.

A especificidade de cada caso, como já foi colocado, pode levar a que devam ser considerados outros fatores. Os aqui citados, contudo, mostram-se recorrentes nos programas de ginástica laboral, logo merecem uma análise criteriosa por parte dos profissionais.

\section{REFERÊNCIAS}

${ }^{1}$ PEROSSI, S. C. A Influência do programa de ginástica laboral na prevenção dos distúrbios osteomusculares relacionados ao trabalho (DORT). 2002. Dissertação (Mestrado em Ciências Médicas) - Faculdade de Ciências Médicas, Universidade Estadual de Campinas, Campinas, 2002.

Conexões: revista da Faculdade de Educação Física da UNICAMP, Campinas, v. 11, n. 2, p. 208-222, abr./jun. 219 2013. ISSN: 1983-9030 
${ }^{2}$ MORENO, E. Estudo do sono em trabalhadores noturnos e a realização da ginástica laboral. 2008. Dissertação (Mestrado em Ciências Médicas) - Faculdade de Ciências Médicas, Universidade Estadual de Campinas, Campinas, 2008.

${ }^{3}$ MASSOLA, R. M. Exercícios físicos na melhoria da qualidade de vida e da capacidade de trabalho e na prevenção da dor e da fadiga entre trabalhadores de fábrica. 2007. Dissertação (Mestrado em Educação Física) - Faculdade de Educação Física, Universidade Estadual de Campinas, Campinas, 2007.

${ }^{4}$ IRJA, H. Success of projects in different organizational conditions: project Management Journal, Finland, 2006.

${ }^{5}$ GONÇALVES, A.; VILARTA, R. Qualidade de vida e atividade física: explorando teoria e prática. Barueri: Manole, 2004.

${ }^{6}$ DUTZ, J. ; ROCHA, S. O modo de vida da mãe e a saúde infantil. Revista Brasileira de Enfermagem, Brasília, v. 55, 2002

${ }^{7}$ BUSS, P. M. Promoção da saúde e qualidade de vida. Ciência \& Saúde Coletiva, v. 5, n. 1, p. 163-177, 2000.

${ }^{8}$ WORLD HEALTH ORGANIZATION (WHO), 2011. Disponível em: <http://www.who.int/en/>. Acesso em: 23 set. 2011.

${ }^{9}$ VARGAS N. Organização do trabalho e capital: um estudo da construção habitacional. 1979. Dissertação (Mestrado em Engenharia e Produção) - Universidade Federal do Rio de Janeiro, Rio de Janeiro, 1979.

${ }^{10}$ CHANG JÚNIOR, J. Motivação através do reprojeto do trabalho. 1995. Dissertação (Mestrado em Qualidade) - Instituto de Matemática, Estatística e Ciência da Computação, Universidade Estadual de Campinas, Campinas, 1995. 
${ }^{11}$ HELOANI, J. R. Organização do trabalho e administração: uma visão multidisciplinar. 4. ed. São Paulo: Cortez, 2002.

${ }^{12}$ FIGUEREDO, F.; ALVÃO, C. M. Ginástica laboral e ergonomia. 2. ed. Rio de Janeiro: Sprint, 2008.

${ }^{13}$ GONÇALVES, A.; GUTIERREZ, G. L.; VILARTA, R. (Org.). Gestão da qualidade de vida na empresa Campinas: IPES, 2005.

${ }^{14}$ SESI. Ginástica na empresa: subsídios técnicos para sua implantação. Brasília: 1996.

${ }^{15}$ LIMA, V. Ginástica laboral: atividade física no ambiente de trabalho. São Paulo: Phorte, 2003.

${ }^{16}$ ALVAREZ, B. R. Estilo de Vida e hábitos de lazer de trabalhadores após dois anos de aplicação de um programa de ginástica laboral e saúde. 2002. Tese (Doutorado em Engenharia de Produção) - Universidade Federal de Santa Catarina, 2002 .

${ }^{17}$ POLITO, E.; BERGAMASHI, E. C. Ginástica laboral: teoria e prática. 2. ed. Rio de Janeiro: Sprint, 2003.

${ }^{18}$ CAÑETE, I. Humanização: desafio da empresa moderna: a ginástica laboral como um caminho. Porto Alegre: Artes e Ofícios, 1996.

${ }^{19}$ VILARTA, R. (Org.). Qualidade de vida e fadiga institucional. Campinas: IPES, 2006.

${ }^{20}$ FACANALI, R. A Influência da gestão empresarial na adesão à ginástica laboral. 2006. Trabalho de Conclusão de Curso - Faculdade de Educação Física, Campinas, 2006. 
${ }^{21}$ MENDES, R. A.; LEITE, N. Ginástica laboral: princípios e aplicações práticas. São Paulo: Manole, 2004.

${ }^{22}$ VILARTA, R.; GUTIERREZ, G. L. Qualidade de vida em propostas de intervenção corporativa. Campinas: IPES, 2007.

${ }^{23}$ VANSAN, N. S. Saúde "versus" lucro: atividade física como fator de qualidade de vida e saúde do trabalhador, diminuindo o índice de absenteísmo e aumentando a produtividade da empresa. In: VILARTA, R; GUTIERREZ, G. L. (Org.). Qualidade de vida e propostas de intervenção corporativa. Campinas: IPES, 2007.

${ }^{24}$ DANIEL, D. R. Management information crisis. Harvard Business Review, v. 39, n. 5, p. 111-121, sept./oct.1961.

${ }^{25}$ ROCKART, J. A new approach to defining the chief executive's information needs. Working Paper, n. 37. Massachusetts: Center for Information Systems Research, 1978.

${ }^{26}$ LIMONGI-FRANÇA, A. C. Qualidade de vida no trabalho - QVT: conceitos e práticas nas empresas da sociedade pós-industrial. 2. ed. São Paulo: Atlas, 2010.

${ }^{27}$ TOLEDO, J. C. et al. Fatores críticos de sucesso no gerenciamento de projetos de desenvolvimento de produtos em empresas de base tecnológica de pequeno e médio porte. Revista Gestão e Produção, São Carlos, v.15, n. 1, p. 117-134, 2008.

Recebido em: 15 dez. 2012

Aceito em: 06 jun.2013

Contato: Gustavo Luis Gutierrez gutierrez@fef.unicamp.br 